http://dx.doi.org/10.18232/alhe.987

Artículos

\title{
El establecimiento del Iva en México: \\ un problema político-económico, 1968-1980
}

\section{The Establishment of vaT in Mexico: A Political-economic Problem, 1968-1980}

María del Ángel Molina $1, *$ (D) 0000-0003-4103-6168

${ }^{1}$ Universidad Nacional Autónoma de México

*Correspondencia: madelangel.molina@gmail.com

Resumen. El artículo pretende explicar el establecimiento del Impuesto al Valor Agregado (IVA) en México con énfasis en los problemas políticos que la federación enfrentó con los diversos actores (estados y contribuyentes) y la manera en que el escenario económico facilitó o entorpeció su imposición. Se sostiene que el conflicto alrededor de la distribución de las facultades tributarias entre la federación y los estados postergó su establecimiento hasta 1980. Sustenta también la idea de que su establecimiento se posibilitó tras la recuperación que la economía mexicana presentó en 1978 a propósito de los ingresos petroleros; y los problemas que implicaría con la iniciativa privada modificar la imposición directa a pesar de que el escenario económico ya no era el adecuado para 1979-1980.

Palabras clave: Hacienda pública; tributación; reformas tributarias; IVA.

Abstract. This article attempts to explain the establishment of the value added tax (vat) in Mexico with emphasis on political problems that the Mexican federation faced with diverse actors (states y taxpayers), and on the way in which the economic scenario allowed or hindered its imposition. It is argued that the conflict

CÓMO CITAR: Molina, M. A. (2020). El establecimiento del IVA en México: un problema político-económico, 1968-1980. America Latina en la Historia Económica, 27(1), e987. DOI: 10.18232/alhe.987 
over the distribution of taxation faculties between the federation and the states delayed the establishing of VAT up to 1980. It is also argued the idea that the recovery that the Mexican economy presented in 1978 with regard to oil revenues, and that the problems that would imply with the private initiative to modify direct taxation even though the economic scenario was no longer adequate for 1979-1980 made possible to establish vat.

Key words: public treasury; taxation; tax reforms; vAT.

JEL: E620; H25; N96.

Recibido: 30 de abril de 2018.

Aceptado: 14 de enero de 2019.

Publicado: 1 de julio de 2019.

Organismo patrocinador: Universidad Nacional Autónoma de México (Programa de Becas Posdoctorales, 2017).

\section{INTRODUCCIÓN}

El objetivo del artículo es explicar el establecimiento del impuesto al valor agregado (en adelante IVA) en México que entró en vigor en 1980 cuando sustituyó al impuesto sobre ingresos mercantiles (en adelante ISIM), vigente desde 1948. Para ello, se pone atención en los problemas políticos que la federación enfrentó con los estados en relación con la distribución de las facultades tributarias y el proceso de centralización tributaria del comercio y la industria, así como con los contribuyentes en tanto agentes económico-políticos capaces de incidir en el fenómeno fiscal. Para entender este tema, así como la problemática que guio la elaboración de esta investigación, es necesario plantear algunas anotaciones previas.

Con el establecimiento del IsIM, la federación buscó acabar con lo que en aquellos años denominó anarquía fiscal para hacer referencia a la concurrencia que resultaba de la imposición simultánea de las diferentes esferas de gobierno sobre las transacciones mercantiles. Bajo esta lógica, con su entrada en vigor se eliminaban las fracciones del antiguo impuesto federal del timbre que recaían sobre los actos comerciales y se pretendía la supresión de los impuestos que las haciendas estatales y municipales tenían sobre el ramo con la intención de que existiera un impuesto único, de carácter federal. Se trató, en pocas palabras, de unificar el ramo. Cabe mencionar que el carácter unificador no fue una característica exclusiva del IsIM. En realidad, desde los primeros años del siglo pasado, una vez concluido el movimiento revolucionario de 1910, las distintas administraciones federales impulsaron un proceso de reorganización hacendaria que respondió a las diversas necesidades financieras y políticas del Estado posrevolucionario en construcción y que definió a la vez, la centralización de facultades tributarias en manos de la federación en la medida en que la unificación se impulsó a través de impuestos federales.

Bajo esta mecánica, con el establecimiento del IsIm se buscó un propósito político: la centralización fiscal del comercio y la industria en manos de la federación. Este objetivo, al implicar un conflicto alrededor de la distribución de las facultades tributarias entre la federación y los estados, dio lugar a un mecanismo transitorio de unificación que inició con la entrada en vigor de la ley federal del IsIm en 1948 y que continuó en la medida en que los estados firmaron convenios con la federación para que suspendieran su facultad de fiscalizar el ramo. A cambio, los estados reci- 
bían una participación de la recaudación del Isım que se cobraba a través de una sobretasa. Esta intención federal fue finalmente alcanzada veinticinco años después cuando todas las entidades federativas suprimieron sus impuestos sobre las transacciones mercantiles en 1973.

Cuando la federación estableció el ISIM en 1947 inició el camino para imponer una figura tributaria que recayera, a diferencia de los impuestos locales que fiscalizaban el comercio y la industria y el mismo ISIM, sobre las ventas finales, es decir, sobre el consumo. En ese entonces, las autoridades federales tomaban como referencia el sell tax vigente en Estados Unidos con la intención de establecer, según afirmaban, una figura tributaria que no obstaculizara el crecimiento económico y el desarrollo comercial e industrial del país, que no generara presiones inflacionarias y que, al mismo tiempo, le permitiera controlar una fuente clave de ingresos tributarios (Yáñez, 1958, p. 328). La federación buscaba mejorar administrativa y técnicamente la fiscalización del ramo y el Isim representaba avanzar hacia un propósito económico-fiscal, que se logró plenamente en 1980 cuando la federación sustituyó el Isim por el IVA tomando como referencia a algunos países europeos que habían establecido esta última figura fiscal desde la década de 1950.

El logro de ambos objetivos -político y económico-fiscal- no fue fácil de conseguir. Con el establecimiento del IsIM se generó un mecanismo en el que se encontraron tres actores y motivaciones: $a$ ) la intención federal por centralizar el ramo y establecer una figura sobre el consumo final, $b$ ) la voluntad de las entidades federativas por mantener sus facultades tributarias sobre dichos sectores y $c$ ) los comerciantes e industriales, en tanto que causantes, que estaban interesados en no afectar su actividad económica. Este encuentro de intereses se registró al mismo tiempo en contextos económicos y políticos determinados que definieron el actuar de cada uno de estos agentes, lo que obligó a que los objetivos aprobados en 1947 se concretaran, con cambios notables, hasta 1980 .

Este planteamiento resulta clave en la medida que representa el marco analítico desde el que estudiaremos el establecimiento del IVA. Se trata de reconocer que su imposición no sólo se inscribe en un proceso fiscal más amplio -el de la coordinación fiscal-, sino también de continuar su análisis desde una perspectiva política-económica que enfatiza la forma en que los intereses de los diversos actores, las tensiones alrededor de estos y los diversos contextos, influyeron en esta.

Así, se puede perfilar de mejor modo el objetivo de este artículo. Se estudia el cómo la federación concretó la coordinación fiscal del comercio y la industria, es decir, el establecimiento de un impuesto al consumo a través del IVA, al subrayar los problemas que este orden de gobierno enfrentó con los diversos actores (entidades federativas y causantes), la manera en que el escenario económico facilitó o entorpeció su imposición y las implicaciones que tuvo en relación con la centralización tributaria del ramo. Esta propuesta analítica que intenta rebasar el estudio del IVA en sí mismo coloca sobre la mesa las cuestiones que guían este artículo: ¿por qué el IVA se estableció hasta 1980 a pesar de que la intención federal por establecer un impuesto al consumo estaba presente desde 1948?, ¿por qué fracasaron los esfuerzos federales de finales de la década de 1960 por establecerlo?, ¿̇por qué se posibilitó su imposición en 1980?, ¿cuál fue la reacción de las entidades federativas y de los causantes? y finalmente, ¿qué representó el establecimiento del iva en términos de la coordinación fiscal entre la federación y los estados?

Para dar respuesta, el artículo se estructura en tres secciones. En la primera, presentamos a manera de antecedentes, las dificultades que enfrentó el proceso de coordinación en la materia desde 1948 hasta la década de 1960 con la intención de evidenciar que el constante conflicto entre la federación y las entidades federativas sobre la distribución de las facultades tributarias del ramo imposibilitó impulsar el establecimiento de un impuesto sobre el consumo final. En la segunda, 
ponemos atención en los esfuerzos federales de finales de la década de 1960 por establecer el IVA, así como en las posibles razones de su fracaso. Es durante este periodo cuando la federación se ve obligada a concluir con la centralización política del ramo en 1973, desdibujando al conflicto en torno a la distribución de las facultades tributarias como un obstáculo para concretar la coordinación del ramo. En la tercera sección, nos concentramos en el establecimiento del IVA, en especial, en los elementos que posibilitaron su establecimiento a pesar de las críticas de carácter económico relacionadas con la oportunidad de establecer una figura tributaria que en un inicio presionaría al alza de precios en un contexto de por sí inflacionario.

La reconstrucción que aquí proponemos constituye una de las ausencias de la historiografía fiscal mexicana del siglo xx. Entre las escasas, pero pioneras investigaciones en relación con el problema fiscal de aquellos años encontramos los trabajos de Luis Aboites (2003) y Graciela Márquez (2012) que al estudiar el proceso de centralización hacendaria que las distintas administraciones federales impulsaron desde las décadas de 1920 y 1970, han abordado en alguna medida la centralización del ramo. Su planteamiento ha enfatizado el componente político de este proceso relacionado con la distribución de las facultades tributarias entre la federación y las entidades federativas sin extender el análisis al establecimiento del IvA. Esperamos en este sentido, complementar estos estudios. Así mismo, pretendemos inscribirnos en la también escasa literatura que ha estudiado la introducción de nuevos impuestos en México durante el siglo xx a partir del papel que juegan los diversos actores (gobierno federal, local y contribuyentes). 1

\section{EL PUNTO DE PARTIDA: LA COORDINACIÓN FISCAL DEL COMERCIO Y LA INDUSTRIA A TRAVÉS DEL ISIM Y LA FALLIDA GENTRALIZACIÓN TRIBUTARIA DEL RAMO}

Tras los fracasados esfuerzos por centralizar la tributación del comercio y la industria de las décadas de 1920 y 1930, la federación mexicana optó por impulsar la coordinación del ramo a través de un mecanismo gradual que inició con la entrada en vigor de la ley federal del IsIM. Este ordenamiento, además de establecer una tasa de 18 al millar (1.8\%) que se aplicó en todo el territorio nacional, invitaba a las entidades federativas a suspender los impuestos locales sobre el ramo a cambio de recibir una participación de la recaudación que se cubriría a través de una sobretasa de quince al millar (1.5\%). En caso de que alguna entidad federativa aceptara la propuesta federal, firmaba con la Secretaría de Hacienda un convenio de coordinación en el que las primeras se comprometían a suspender su soberanía sobre el ramo.

Este mecanismo bien podemos ilustrarlo si retomamos, por ejemplo, el caso de Morelos que fue una de las primeras entidades federativas en coordinarse; según se lee en el convenio celebrado en enero de 1950, esta entidad se comprometía a sólo percibir como impuestos sobre el comercio y la industria, la cuota adicional que establecía el artículo $8^{\circ}$ de la ley federal del Isim. Así, la quinta base establecía:

Quinta. - Si los poderes del Estado de Morelos expiden disposiciones contrarias a la Ley Federal del Impuesto Sobre Ingresos Mercantiles y a las estipulaciones del presente convenio, la Secretaria de Hacienda quedará desligada de todo compromiso y continuará cobrando por conducto de sus dependencias, solamente la cuota federal del dieciocho al millar (Diario Oficial de la Federación, 1950).

\footnotetext{
${ }^{1}$ Véanse, por ejemplo, Elizondo (1994), Molina (2016) y Unda (2017); para cuestiones metodológicas, véase Lie-
} berman (2002). 
Cada entidad federativa podía ejercer de nueva cuenta su soberanía tributaria sobre el ramo al momento que así lo decidiera. Si esto sucedía, la federación seguiría cobrando únicamente las tasas de 18 al millar. En este sentido, en el marco de la ley federal que dio vigencia al isim en 1948, la posibilidad jurídica de este y demás convenios tenía su principal sustento en la sobretasa que se ofrecía como incentivo a la coordinación.

Sin embargo, la federación enfrentó dificultades que la obligaron a modificar en diversas formas la mecánica establecida. El primer cambio de gran envergadura surgió a propósito de los causantes. El 4 de febrero de 1948, apenas un mes después de la entrada en vigor de la ley federal del ISIM, un conjunto de contribuyentes encabezados por la Confederación de Cámaras Nacionales de Comercio (Concanaco) emitieron un comunicado (Memorial, 4 de febrero de 1948) en el que expresaban su disgusto por la sobretasa del quince al millar por considerarla excesiva. Su reclamo se originaba a propósito del esquema de doble tasa que se había establecido para la coordinación. De esta mecánica, los causantes que operaran en estados coordinados pagarían ambas tasas que sumaban una cuota del 33 al millar. En cambio, los causantes que realizaran operaciones en estados no coordinados sólo pagarían la tasa de 18 al millar que, al tener vigencia nacional, no dependía de la coordinación. Además, argumentaban, se generaba una carga adicional en la transacción mercantil por el efecto cascada del IsIm (Memorial, 4 de febrero de 1948, p. 2).

Los causantes demandaban entonces, la reducción de la sobretasa invitando a las entidades federativas, incluso, a no coordinarse hasta que se estableciera una tasa justa del impuesto (Memorial, 4 de febrero de 1948). Ante la importante oposición que las entidades federativas habían mostrado hacia la centralización del ramo durante las décadas anteriores y el ya significativo peso económico de las organizaciones de comerciantes e industriales, la federación no dudó en ceder. En diciembre de ese mismo año redujo la sobretasa a doce al millar respondiendo, según señalaba Beteta (1951, p. 365) a las "justificadas quejas de los causantes". De esta manera, se fijó un tope en los incentivos que la federación ofrecía a través de la participación, dando lugar a otros alicientes establecidos entre 1949 y 1953, que incluyeron la facultad -para las haciendas estatales- de establecer impuestos especiales sobre el ramo y la participación de 40 \% sobre las multas y recargos recaudados por concepto de ISIM.

Bajo este conjunto de incentivos Aguascalientes, Morelos, Querétaro, Tlaxcala, Michoacán, Sinaloa, San Luis Potosí, Colima, Yucatán, Durango, Hidalgo, Campeche, Tabasco y Puebla -el Distrito Federal, Quintana Roo y Baja California Norte, coordinados desde 1948- se sumaron a los territorios federales al firmar convenio entre 1949 y 1955 . El último estado en acceder a la coordinación bajo este esquema fue Guerrero en 1957. A partir de entonces, no se celebraron nuevos convenios de coordinación hasta los primeros años de la década de 1970. Este largo periodo denota, entre otras cuestiones, que los esfuerzos federales no resultaron para catorce entidades federativas: Chihuahua, Nayarit, Tamaulipas, Jalisco, Nuevo León, Sonora, Oaxaca, Guanajuato, Veracruz, Coahuila Zacatecas, Chiapas, Baja California Sur y el Estado de México.

Es necesario revisar tanto la discusión, como la posición de los diversos actores locales para explicar por qué estas entidades federativas no firmaron un convenio de coordinación con la Hacienda federal. No obstante, tal revisión está fuera del alcance y objetivos de este artículo. La mayor parte de estas entidades federativas reportaban una actividad económica importante. Eran las entidades federativas no coordinadas las que más aportaban al PIB nacional con tasas que rebasaban la participación media nacional (identificada con la línea vertical en el gráfico 1) de 3.1 \% y que oscilaban entre $3.2 \%$, correspondiente a Baja California Sur y a Coahuila, y 7.1\%, al Estado de México. Esta entidad, era seguida por Nuevo León, Veracruz y Jalisco cuya participación alcanzaba 


\section{GRÁFICA 1. PRODUCTO INTERNO BRUTO POR ENTIDAD FEDERATIVA, MÉXICO, 1970 (PORCENTAJES)}

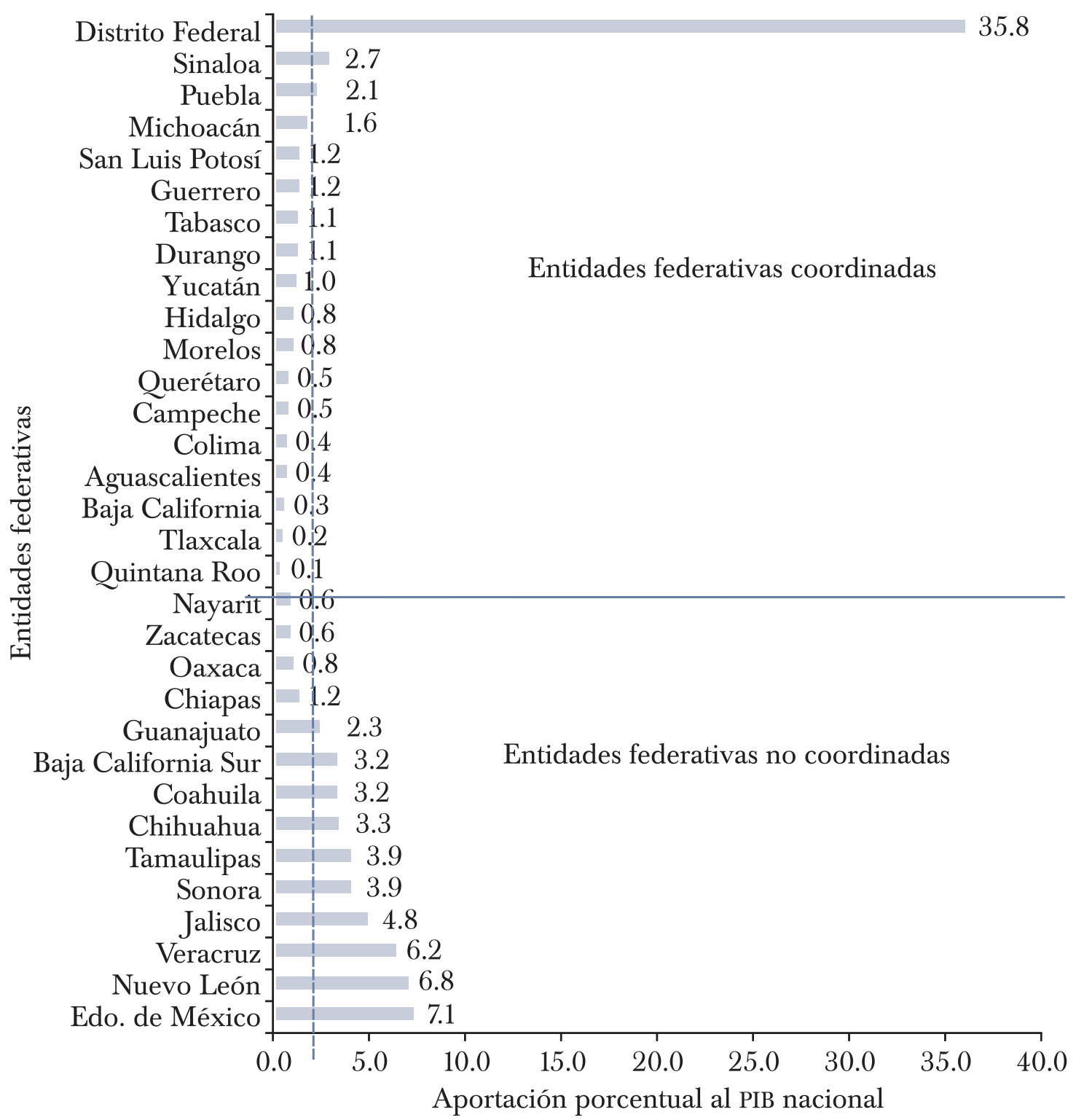

Fuente: elaboración propia con base en México. Subsecretaría de Ingresos (1973).

6.8, 6.2 y $4.8 \%$, respectivamente. Sonora, Tamaulipas, Chihuahua y Coahuila superaban $3 \%$ del Producto Interno Bruto (PIB) total. Guanajuato, Chiapas, Oaxaca, Zacatecas y Nayarit reportaban una participación por debajo de la media nacional (véase gráfica 1).

En cambio, todas las entidades coordinadas, excluyendo al Distrito Federal cuya aportación alcanzaba $35.8 \%$, tenían una participación por debajo de la media nacional. Quintana Roo, Tlaxcala, Baja California Norte, Aguascalientes, Colima, Campeche, Querétaro, Morelos, Hidalgo y Yucatán tenían una participación mínima en la generación del PIB que variaba entre 0.01 y 1 \%. Le 
seguían estados como Durango, Tabasco, Guerrero, San Luis Potosí y Michoacán que no rebasaban $2 \%$. Puebla con $2.1 \%$ y Sinaloa con $2.7 \%$ representaban las entidades coordinadas que más aportaban al PIB. Estas 17 entidades, en su conjunto, sólo generaban $16.2 \%$ del PIB. En cambio, los catorce estados no coordinados producían $48 \%$. En correspondencia a esta situación, fueron también estos estados los que más aportaban a la recaudación federal del IsIM que correspondía a la tasa general de 1.8 por ciento.

Las entidades federativas no coordinadas eran las que más aportaban a la federación por este concepto (43.28\%). La baja participación de Oaxaca, Chiapas, Nayarit, Baja California Sur y Zacatecas se explica a partir de que el sector agrícola tenía en su respectiva actividad económica. En cambio, las entidades coordinadas aportaban, en su conjunto, apenas el $13.7 \%$ de la recaudación federal del Isim. (véase gráfica 2).

\section{LOS PRIMEROS Y FRACASADOS ESFUERZOS FEDERALES POR ESTABLECER EL IVA} Y LA CONCLUSIÓN DE LA CENTRALIZACIÓN FISCAL DEL COMERCIO Y LA INDUSTRIA, 1968-1977

Los primeros esfuerzos federales por establecer el iva se ubican a finales de la década de 1960, es decir, antes de que el objetivo político de la coordinación fiscal del ramo hubiera concluido. Estos intentos no pueden ser entendidos sin considerar los cambios tributarios que se estaban impulsando a nivel internacional a propósito de los esfuerzos que la Comunidad Económica Europea emprendió en 1967 por homologar la fiscalidad indirecta de los países miembro y el compromiso adquirido por el gobierno mexicano por impulsar los cambios fiscales que posibilitaran la futura conformación del Mercado Común Latinoamericano 22 En ambos espacios de integración económica, el llamado fue a sustituir los gravámenes que recaían sobre el volumen de negocios por el IVA con la intención de contar con una legislación en la materia que no falseara las condiciones de competencia, al tiempo que facilitara la libre circulación mercantil. En este contexto, el establecimiento de esta figura tributaria comenzó a tener lugar en los países latinoamericanos entre los que destacaron Uruguay, Brasil y Costa Rica que lo incorporaron ese mismo año (García, 1982). En el marco de estos acontecimientos, el gobierno federal mexicano inició en 1968 los primeros esfuerzos formales por establecer el IVA. ¿En qué consistieron y cuál fue la posición de los actores involucrados?

El programa federal de trabajo coordinado y dirigido por Roberto Hoyo D’Addona, entonces director del Departamento de Estudios Técnicos de la Administración General de Impuestos de la Secretaría de Hacienda, comprendió en primer lugar, la elaboración de un Anteproyecto del IVA en México, dado a conocer en noviembre de 1968. El documento (Parás y Jiménez, 1972) constituido por ocho capítulos establecía las bases del nuevo gravamen que al igual que el Isim,

\footnotetext{
${ }^{2}$ A partir de la segunda mitad de la década de 1950, la mayoría de los países europeos introdujo el rva. Francia encabezó la transición en 1954 (Egret, 1979). Sin embargo, su imposición cobró mayor impulso a partir de 1967 cuando la Comunidad Económica Europea (CEE) decidió homologar los sistemas de tributación indirecta a través del IVA. La intención de esta reforma fue, según señala la directiva que emitió el Consejo de la cEE el 11 de abril de 1967, el establecimiento de una legislación que facilitara el intercambio comercial. (Comunidad Económica Europea, 1967). En el mismo año, y de manera paralela al proceso de integración europea, se celebró en Punta del Este, Uruguay, la reunión en la que dirigentes de varios países latinoamericanos -incluido México- asumieron, a través de la Declaración de los Presidentes de América (1967), el compromiso de crear de forma progresiva, a partir de 1970, el Mercado Común Latinoamericano. En el proceso de integración, que no debería demorar más de quince años -según señalaba el mismo documento-, se debía impulsar también, a través del IVA, la eliminación programada de gravámenes con la intención de no obstaculizar el comercio en la región (Declaración de los Presidentes de América, 1967, p. 538).
} 


\section{GRÁFICA 2. RECAUDACIÓN FEDERAL DEL ISIM POR ENTIDAD FEDERATIVA,} MÉXICO, 1970

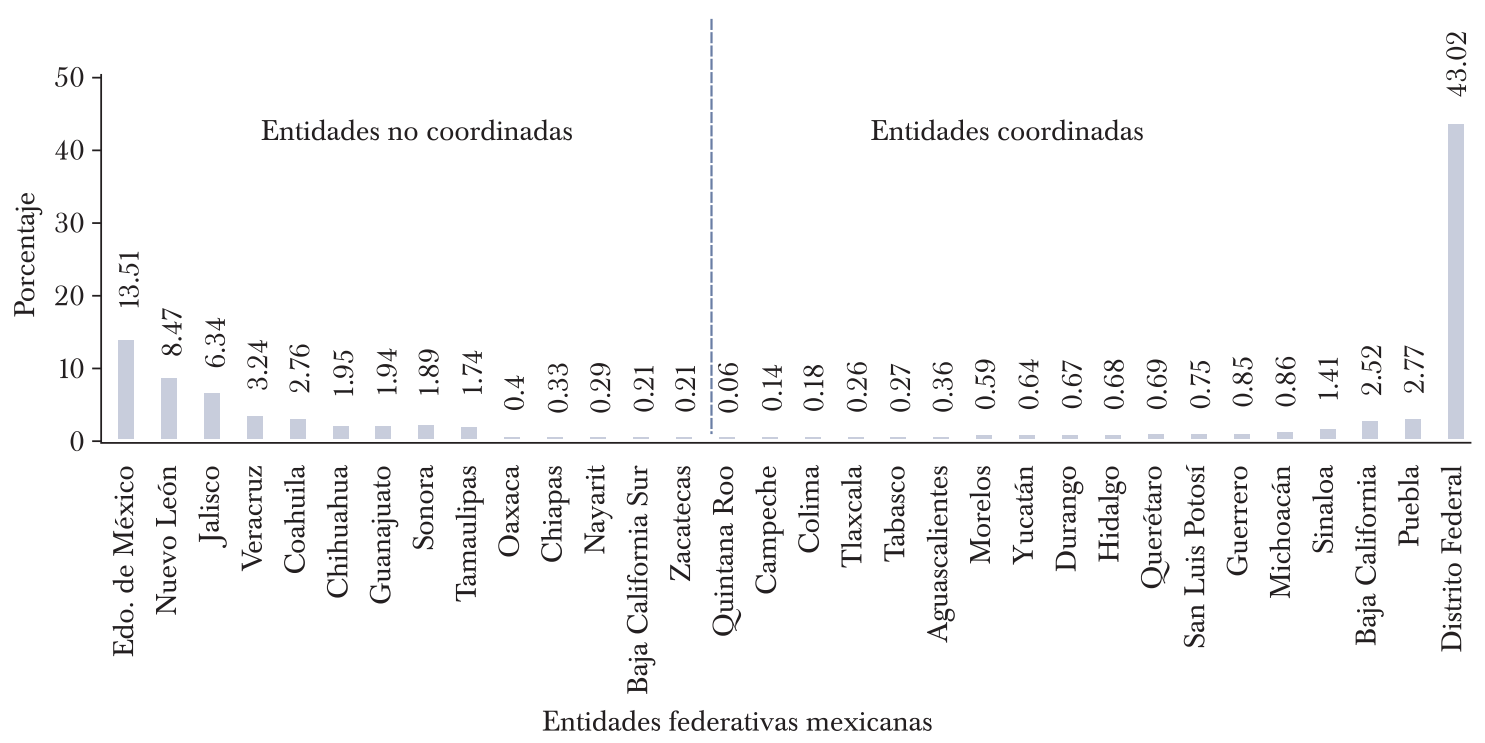

Fuente: elaboración propia con base en Instituto para el Desarrollo Técnico, Hacienda Pública de Estados y Municipios (1975).

recaía sobre las ventas. Su diferencia principal en todo caso, además de ser un impuesto al consumo final, era su capacidad de anular el efecto acumulativo (o en cascada) sobre los precios. Lo anterior obedecía a que el causante sólo debía enterar al fisco, la diferencia entre el impuesto que había cobrado al consumidor (al momento de realizar su venta) y el impuesto que había pagado al momento de comprar sus insumos. De esta manera, cada agente económico de la cadena de producción y distribución, al recuperar el impuesto que había pagado a sus proveedores, no tenía razón alguna para considerar a este dentro de sus costos de producción como sí lo hacía bajo el esquema del IsIM. De esta mecánica surgía también una diferencia por demás importante: en la medida en que el contribuyente sólo entregaba al fisco la diferencia entre el impuesto que había trasladado y el que le habían trasladado, estaba en realidad adelantando únicamente una parte del impuesto que el consumidor final debería pagar. El Iva en pocas palabras, es un impuesto que grava el consumo final de manera fraccionada. En el Anteproyecto también se proponía sustituir la cuota federal del Isim de 18 al millar (1.8\%) por una general de $5 \%$ y una especial de $15 \%$ para artículos de lujo ${ }^{3}$

Según Parás y Jiménez (1972), una vez que se dio a conocer el anteproyecto, numerosas personas y organizaciones llevaron a cabo estudios en torno a sus disposiciones. Hasta el momento no se cuenta con evidencia de algún pronunciamiento por parte de las entidades federativas. Lo cierto también es que, en la elaboración del mismo, estas no fueron las interlocutoras del gobierno federal. De lo que sí se tiene noticia es de un documento (Escoto, 1972) enviado en diciembre de ese año a Roberto Hoyo por parte de la Confederación de Cámaras Nacionales de Comercio, la

\footnotetext{
${ }^{3}$ En este estudio no se hace ninguna alusión a las razones por las que las tasas se establecieron en ese nivel. Sin embargo, podemos pensar que la tasa de $5 \%$ establecida en el anteproyecto sirvió de referencia para el incremento a $4 \%$ en la tasa general del Isım establecido en 1973, véase Parás y Jiménez (1972).
} 
Confederación Patronal de la República Mexicana, la Asociación Mexicana de Seguros de Crédito, la Asociación de Banqueros de México y la Confederación de Cámaras Industriales (en adelante Concamin) en el que daban a conocer sus puntos de vista y observaciones sobre el Anteproyecto (Escoto, 1972). En el documento, las organizaciones no pronunciaron un absoluto rechazo al establecimiento del IvA, pero sí señalaron su inaplicabilidad acusando al anteproyecto de confuso e incompleto. Entre los señalamientos que expresaron destacan dos. El primero es el carácter inflacionario que la novedad podría provocar. Al respecto señalan:

Suponiendo sin conceder que efectivamente las industrias realicen estudios de costos posteriores que las convenzan que puedan abatir sus precios habida cuenta de la repercusión que hicieron del impuesto, no cabe duda que este ajuste llevará tiempo para realizarlo: si se toma en consideración que la ley entrará en vigor en octubre de 1969 y en diciembre del mismo año deberán revisarse los salarios mínimos con aplicación en toda la República, lógicamente se presentará una situación de inflación de precios en el peor momento (Escoto, 1972, pp. 237-238).

El segundo es el relacionado con la coordinación. Para estas organizaciones, el diseño del IVA rompería con los avances logrados en ese sentido. ¿Qué quería decir un señalamiento como este? La tasa general de $5 \%$ propuesta en el anteproyecto sólo se contempló con la intención de sustituir la cuota federal de $1.8 \%$, manteniendo la cuota local del IsIM de $1.2 \%$. Bajo esta lógica, el causante que realizara transacciones en estados coordinados se encontraba con serias dificultades en la medida en que debía realizar dos declaraciones mensuales: una para cubrir el nuevo impuesto federal y otra para enterar la cuota local del ISIM $4^{4}$ Un reconocido fiscalista de aquellos años, Alberto Parás Pagés, quien también tuvo participación en el estudio del anteproyecto, afirmaba que de haber entrado en vigor la propuesta: "Se obligaría a los estados coordinados a elaborar una nueva ley local que regulara el IIIM, ya que actualmente dichas entidades federativas basan su recaudación exclusivamente en la Ley Federal. Así mismo, los estados coordinados, que son los más pobres de la república, se verían forzados a administrar su nuevo impuesto que sería muy gravoso porque los obligaría a crear nuevos organismos" (Parás y Jiménez, 1972, p. 90).

Emitir una nueva reglamentación para el cobro de la tasa local de $1.2 \%$ del ISIM implicaría abonar al problema de la concurrencia fiscal, que era lo que buscaba corregir la coordinación. Además, en ese momento, cuando las entidades federativas de mayores recursos se habían mantenido al margen de esta, tampoco convenía mucho alterar el proceso cambiando la tasa federal de $1.8 \%$ por la del IVA, manteniendo como incentivo la tasa de $1.2 \%$ del ISIM.

A la observación relacionada con la coordinación del ramo se agregó, a través de un memorándum (Parás y Jiménez, 1972, pp. 361-363) elaborado por una comisión de especialistas enviada por la Coparmex y la Concamin a estudiar el establecimiento del iva a varios países europeos, la recomendación -en caso de establecerlo en México- de abrir un plazo mínimo de seis meses para que los contribuyentes conocieran y aprendieran el manejo del nuevo impuesto y ajustaran sus sistemas contables.

\footnotetext{
${ }^{4}$ El cálculo de ambos impuestos implicaba una base distinta. Según el anteproyecto, el iva se declararía con base en la diferencia entre el impuesto que el contribuyente cobró al realizar una venta y el que pagó al momento de comprar a sus proveedores. El ISIM en cambio, se aplicaba al ingreso total obtenido por operaciones de compraventa sin que existiera la oportunidad de recuperar el impuesto pagado en transacciones anteriores.
} 
De manera simultánea a las recomendaciones de los contribuyentes, la federación resolvió constituir, a través de la Dirección de Auditoría Fiscal Federal, un conjunto de comisiones integradas por funcionarios federales, especialistas fiscales y representantes de la banca, la industria y el comercio para estudiar temas relacionados con la instauración del IVA. Entre estos, destaca el objeto mismo del impuesto, el reglamento para el pago de causantes mayores y menores, las deducciones, las devoluciones, los requisitos de contabilidad, de facturas, así como lo referente a las exenciones ${ }^{5} \mathrm{Si}$ bien no es objeto de este artículo, la lectura general de los hallazgos que resultaron de cada una de estas comisiones permite afirmar la existencia de un sinnúmero de inconvenientes técnicos para el establecimiento del IVA. ${ }^{6}$

La Secretaría de Hacienda resolvió entonces, no enviar el anteproyecto al Congreso, pero sí proponer un proyecto de ley que se dio a conocer en octubre de 1969. Este nuevo documento (Parás y Jiménez, 1972) si bien recoge aspectos de las recomendaciones que realizaron las comisiones recién señaladas, no contiene modificaciones sustanciales respecto al anteproyecto de 1968, salvo la relacionada con la situación de las entidades coordinadas. En este nuevo intento por establecer el IVA, se proponía una tasa general de $8 \%$ con el propósito de incluir una participación del rendimiento de esta para dichas entidades federativas y eliminar, en su caso, la tasa local del IsIM. La participación cuya vigencia no excedería los cinco años, debía ser acordada entre cada estado y el gobierno federal. La situación con los estados no coordinados se mantenía bajo el formato propuesto en el anteproyecto de 1968, es decir, una tasa general de 5 por ciento.

La propuesta de 1969 si bien intentaba resolver el problema con las entidades federativas hasta el momento coordinadas en tanto que establecía una tasa general única que incluía una participación para la hacienda local, dificultaba las transacciones entre estos y los estados no coordinados. Para entender esta afirmación, se puede suponer, por ejemplo, la venta de un producto fabricado en un estado coordinado a un estado no coordinado. Bajo la lógica que recién se ha descrito, el productor debía pagar a sus proveedores $8 \%$ por concepto de IVA y cobrar al momento de la venta de su producto, una tasa de $5 \%$. Así, tendría que trasladar al precio final del bien, el iva que no podría reembolsarse, es decir, $3 \%$ de diferencia entre $8 \%$ que pagó en el estado coordinado y $5 \%$ que cobró en el estado no coordinado. En palabras de Parás y Jiménez (1972), esta situación era tanto como establecer un "IVA con efecto en cascada". Con esta circunstancia se quebrantaba, por supuesto, uno de los pilares fundamentales del Iva.

Con la información hasta ahora disponible se desconoce si las organizaciones de causantes o las entidades federativas se pronunciaron alrededor de este nuevo esfuerzo. Lo que sí se sabe es que el proyecto tampoco llegó al Congreso. Las dificultades recién expuestas, sin duda alguna, obligaron a la federación, en alguna medida a abandonar por el momento su intención por establecer el IvA. Lo cierto también es que los esfuerzos impulsados a través del anteproyecto de 1968 y el proyecto de 1969 evidenciaron a las autoridades federales la importancia de concluir previamente con la centralización fiscal del ramo si se pretendía establecer una figura tributaria sobre el consumo final. Más valía concluir el objetivo político de la coordinación con una figura tributaria ya obsoleta, es decir, el ISIM, que adicionar una figura que, por su novedad, complicaría mucho más el escenario.

\footnotetext{
${ }^{5}$ Para resultados de estudios, véase Parás y Jiménez (1972).

${ }^{6}$ Las comisiones constituidas fueron diecinueve, sobre los temas que abordaron véase Parás y Jiménez (1972, pp. 2021).
} 
Fue en 1973 cuando el interés federal por concluir la centralización fiscal del ramo tomó un carácter ineludible debido a la imperiosa necesidad por incrementar los ingresos tributarios. Tras la importancia que adquirió en la política económica a partir de 1972 el gasto público expansionista y la falta de voluntad política por reformar el ISR a finales del mismo año, el gobierno federal optó con intenciones recaudatorias, por modificar el IsIM estableciendo una tasa única de $4 \%$ (véase Elizondo, 1994). Con este cambio se dejaba atrás aquella composición que establecía una tasa federal de $1.8 \%$ y una adicional para las entidades federativas de $1.2 \%$ y se aumentaba al mismo tiempo, la participación que le correspondía a las entidades federativas. Con el sistema de tasas que había prevalecido hasta el momento, 40 \% de la recaudación del IsIM le correspondía a la entidad federativa coordinada y $60 \%$ a la federación. Ahora, con la modificación de 1973, se proponía una nueva distribución en la recaudación total: $45 \%$ para la hacienda local y $55 \%$ para la federación.

Esta reforma -en la composición y el nivel de la tasa del IsIM- representó un instrumento de coerción político-fiscal para las entidades federativas que no se habían coordinado hasta el momento. Si se considera que la tasa del Isim para estas entidades, al pasar de 1.8 a $4 \%$, incrementó $122 \%$, es evidente que la federación forzó la incorporación de las entidades federativas que aún faltaban.7 Cómo señaló Jorge Navarro, delegado de Chihuahua en el marco de la celebración de la Tercera Reunión Nacional de Tesoreros, con la imposición de una tasa federal única de 4 \%, los convenios de coordinación se convirtieron "prácticamente indenunciables por parte de los Estados, ya que los contribuyentes no podrían soportar el impuesto local al comercio y a la industria y el federal sobre ingresos mercantiles" (Navarro, 1973, p. 210).

Tras esta reforma, no hubo mayor alegato por parte de las entidades federativas debido a la existencia de elementos que mitigaron el conflicto. Uno de estos es el incremento que la recaudación total del IsIm presentó después de ese año. Entre 1971 y 1972, es decir, un año fiscal anterior a la reforma, la tasa de crecimiento promedio de la recaudación del IsIM alcanzó $12.5 \%$ (véase cuadro 1). En cambio, entre 1973 y 1974, apenas un año después de que se coordinaran todas las entidades federativas, la tasa de crecimiento ascendió hasta alcanzar $40.9 \%$. Este monto mayor de recaudación junto con la tasa de 45 \% que les correspondía a las haciendas locales bajo el nuevo esquema, permitieron incrementar de manera considerable las participaciones que le correspondían a estas. No en vano, Carlos Hank González, gobernador del Estado de México, e Ignacio Pichardo Pagaza, secretario general, afirmaban "profundamente satisfechos" que, para el gobierno local, la firma del acuerdo representaría un incremento inmediato de los ingresos locales que giraría alrededor de los 100000000 de pesos (México. Secretaría de Hacienda y Crédito Público, 1973, p. 30).

Fue así que la federación concluyó la centralización del ramo, abriendo más posibilidades políticas para retomar su intención por establecer el rva. Sin embargo, el desempeño que la economía mexicana presentó hasta 1977 no dio oportunidad para impulsar un nuevo esfuerzo. Durante ese periodo señalan Moreno-Brid y Ros (2010) se perdió la estabilidad macro de los años anteriores y la tasa de crecimiento del PIB, si bien tuvo un repunte en 1973, disminuyó de manera considerable hacia finales de la década de 1970. Entre 1971 y 1976 por ejemplo, dicha tasa alcanzó, en promedio anual, 6 \%. En cambio, para 1977, apenas llegó a 3.4 \%. La inflación, por su parte, presentó

\footnotetext{
${ }^{7}$ Para el caso de las entidades federativas que ya estaban coordinadas el incremento no fue tan drástico. En estas, la tasa general del Isim alcanzaba $3 \%$ ( $1.8 \%$ de la tasa local y $1.2 \%$ que correspondía a la tasa local). Con la reforma de 1973 que colocaba una única tasa de $4 \%$, el incremento sólo fue de 33 por ciento.
} 


\section{CUADRO 1. TASA DE CRECIMIENTO DEL ISIM POR ENTIDAD FEDERATIVA, 1971-1974}

\begin{tabular}{lcl}
\hline & \multicolumn{2}{c}{ Años } \\
Entidad federativa & $1971-1972$ & $1973-1974$ \\
\hline Aguascalientes & 12.99 & 33.47 \\
Baja California & 9.28 & 29.4 \\
Baja California Sur & 15.29 & 47.17 \\
Campeche & 23.4 & 54.83 \\
Coahuila & 10.87 & 25.19 \\
Colima & 18.03 & 40.99 \\
Chiapas & 4.61 & 33.38 \\
Chihuahua & 18.3 & 42.6 \\
Distrito Federal & 10.06 & 32.99 \\
Durango & 13.18 & 43.91 \\
Guanajuato & 0.24 & 40 \\
Guerrero & 23.6 & 26.19 \\
Hidalgo & 34.96 & 62.39 \\
Jalisco & 16 & 27.15 \\
Estado de México & 8.96 & 42.82 \\
Michoacán & 12.1 & 46.35 \\
Morelos & 12.67 & 39.63 \\
Nayarit & 14.63 & 23.53 \\
Nuevo León & 8.5 & 37.91 \\
Oaxaca & 0.32 & 47.22 \\
Puebla & 13.02 & 37.4 \\
Querétaro & 16.26 & 48.04 \\
Quintana Roo & 19.51 & 73.81 \\
San Luis Potosí & 11.84 & 30.17 \\
Sinaloa & 23.04 & 36.52 \\
Sonora & 2.78 & 49.72 \\
Tabasco & 20.71 & 36.05 \\
Tamaulipas & 12.82 & 36.2 \\
Tlaxcala & 9.77 & 46.31 \\
Veracruz & -0.43 & 42.08 \\
Yucatán & 12.5 & \\
Zacatecas & & \\
Promedio nacional & & \\
\hline
\end{tabular}

Fuente: elaboración propia con base en Instituto para el Desarrollo Técnico, Hacienda Pública de Estados y Municipios (1975).

un incremento por demás considerable: entre 1971 y 1976, la tasa de inflación anual promedio alcanzaba los 14.9 puntos porcentuales que rebasaba por mucho el $3 \%$ que se había mantenido entre 1958 y 1970 (Moreno-Brid y Ros, 2010, pp. 170-196). 
En la exposición de motivos de la ley de ingresos que presentó José López Portillo a la Cámara de Diputados en diciembre de 1977, reconocía que la administración tributaria debía considerar la existencia de una crisis de crecimiento que no estaba del todo resuelta (Ibarra, 1980, p. 14). En ese marco, afirmaba que el ejecutivo a su cargo "no [había] juzgado pertinente" proponer iniciativas de ley que modificaran "significativamente la estructura tributaria y la carga fiscal, ya sea de personas físicas o empresas" (Ibarra, 1980, p. 26). Los objetivos en ese momento eran alcanzar tasas moderadas de crecimiento - si se comparaban con las del decenio anterior- que fueran congruentes con las exigencias de superar el proceso de reajuste que se impulsó tras la devaluación de 1976, combatir la inflación y corregir los desequilibrios financieros y de pagos externos (Ibarra, 1980, p. 15). Lo anterior no se traducía por supuesto en una absoluta inmovilidad de la federación respecto a los problemas tributarios. Lo que advirtió en su discurso fue la intención presidencial por llevar a cabo "modificaciones más convenientes", que, si bien no podían impulsarse por la coyuntura, sí debían permitir al sistema tributario nacional en su conjunto responder a la evolución económica y social del país para convertirlo en una herramienta más apta de equidad social y fomento a la producción (Ibarra, 1980, pp. 15-28).

\section{El ESFUERzo EXITOSO, 1978-1980}

El último periodo de rápido crecimiento que experimentó la economía mexicana antes de la crisis de los años ochenta inició en 1978 tras la actividad económica que trajo consigo el descubrimiento de los yacimientos petroleros de Cantarell en Campeche y Tabasco. Los crecientes ingresos petroleros que las arcas públicas recibieron a partir de entonces y la confianza gubernamental de sostener el ritmo de crecimiento representaron una oportunidad importante para que, en circunstancias financieras propicias, México reestructurara su organización económica (Gracida, 2002, p. 130). De 1978 a 1979, las rentas petroleras como proporción del PIB registraron un incremento por demás considerable al pasar de $2.3 \%$ a 7.4 \% (Banco Mundial, 2018) permitiendo un superávit fiscal de más de 122000000 de pesos a finales de 1979 que superaba por mucho el registrado en años anteriores 8 (Instituto Nacional de Estadística Geografía e Informática, 1999, p. 630). Por su parte, la tasa de crecimiento económico del PIB en 1978 registró un repunte considerable que, al alcanzar los nueve puntos porcentuales, superó por mucho la tasa de crecimiento del año anterior de $3.4 \%$ (Cabrera, 2011, p. 71).

De esta forma, se definió el escenario económico que incentivó al gobierno federal a reiniciar el intento por establecer el IVA que había dejado pendiente el año anterior: no había urgencia recaudatoria debido a los excedentes petroleros registrados y existía un ritmo de crecimiento que, al gravarse a través del consumo, se estrecharía con la recaudación. A diferencia de los intentos anteriores que respondieron a intenciones recaudatorias, en el discurso federal de finales de los setenta, el nuevo esfuerzo se reconoció a partir de la importancia de elevar la capacidad de respuesta del sistema tributario para participar en los incrementos del ingreso nacional y con ello, abonar a través de la imposición indirecta, a la corrección de los problemas estructurales del sistema tributario nacional (Ibarra, 1980, p. 155). Al respecto, López (1980) en la exposición de motivos de

\footnotetext{
${ }^{8}$ El superávit registrado durante 1979 representó el más alto desde 1973. En 1978, por ejemplo, los ingresos del gobierno federal rebasaron sus egresos en 12813000 pesos (Instituto Nacional de Estadística Geografía e Informática, 1999, p. 630).
} 
la iniciativa de ley de ingresos de la federación que presentó el 15 de diciembre de 1977 ante la Cámara de Diputados, reconoce las iniciativas fiscales que se propondrían, como un proceso de modernización:

[...] el Ejecutivo Federal mantiene el firme compromiso de transformar y adecuar el sistema tributario federal. Después de realizar los estudios indispensables, examinar en detalle las repercusiones y efectuar consultas, se propondrán con oportunidad las modificaciones más convenientes, dentro de una estrategia que concibe a la Reforma Fiscal no como un acto súbito y discontinuo, sino como un proceso permanente de actualización y modernización, congruente con la evolución y grado de cumplimiento de las metas de desarrollo (López, 1980, p. 28).

Casi un año después, en noviembre de 1978, el ejecutivo federal envió al Congreso de la Unión la iniciativa para establecer el Iva que fue aprobada ese mismo mes. Así, en diciembre de 1978, se publicó la Ley del Impuesto al Valor Agregado, que entraría en vigor el 1 de enero de 1980 (Congreso de los Estados Unidos Mexicanos, 1978). Para la elaboración del proyecto que sustentó dicha ley, el gobierno recibió, a diferencia de las propuestas de 1968 y 1969 en las que había echado mano de comisiones integradas por especialistas nacionales, un comité del Fondo Monetario Internacional dirigido por Alan A. Tait, economista partícipe en otras experiencias internacionales (Anónimo, 2009). Un estudio comparativo y pormenorizado entre dicho proyecto y sus antecesores nos permitirá dar cuenta de las diferencias existentes entre éstos. Pero lo cierto es que en términos de las características generales del impuesto no existen diferencias significativas. En el artículo $1^{\circ}$ de la ley del Iva aprobada por el Congreso, se establece:

Están obligadas al pago del impuesto al valor agregado establecido en esta Ley, las personas físicas, las morales o las unidades económicas que, en territorio nacional, realicen los actos o actividades siguientes:

I. Enajenen bienes

II. Presten servicios independientes

III. Otorguen el uso o goce temporal de bienes

IV. Importen bienes y servicios

El impuesto se calculará aplicando a los valores que señala esta Ley la tasa del $10 \%$. El impuesto al valor agregado en ningún caso se considerará que forma parte de dichos valores (Congreso de los Estados Unidos Mexicanos, 1978).

El objeto gravable del IVA, al igual que el IsıM, era en términos genéricos, la venta de bienes y servicios $\int^{9}$ Pero a diferencia de este último, el primero dejaba de considerar al ingreso del oferente como la base sobre la que se calcularía el impuesto. Ahora se estimaría sobre el valor agregado en

\footnotetext{
${ }^{9}$ Según se lee en el artículo $1^{\circ}$ este impuesto se causaba sobre los ingresos obtenidos por concepto de ventas, prestación de servicios, comisiones, consignaciones, agencias, agencias de turismo, representaciones, corretajes o distribuciones y sobre los ingresos de cabarets, pulquerías, cantinas, piquerías y demás expendios de bebidas embriagantes. Ahora bien, si ponemos atención en la diversidad de rubros que contempla el objeto grabable del isim caemos en cuenta de que es una figura que recae en términos genéricos, sobre las ventas de bienes y servicios realizadas por personas físicas o morales (ya sea industriales y/o comerciantes) (México. Subsecretaría de Ingresos, 1976).
} 
cada una de las etapas de la circulación mercantil, es decir, el causante sólo pagaría la diferencia entre el impuesto que le fue trasladado (al momento de comprar sus insumos) y el que trasladó (al momento de realizar sus ventas). De aquí, surgía la capacidad de anular el efecto acumulativo (o en cascada) sobre los precios que sí tenía el Isim y se justificaba que la tasa introductoria del iva de $10 \%$ rebasara el $4 \%$ con la que el primero grababa. Un ejemplo de esta mecánica lo encontramos en las consideraciones que la Concamin realizó en 1980:

Con este impuesto [IVA] si se adquiere una materia prima en 100 y se le repercute el $10 \%$ se tendrá un pago de 110 . Si en una segunda etapa el artículo se vende en 200 , el productor o comerciante va a poder restar el impuesto que le fue trasladado. O sea, no es un impuesto acumulativo o que incida en los costos de los productos, sino que es un impuesto de los que se dicen "van por fuera".

Si utilizamos el lenguaje contable, se puede decir que "el impuesto que me fue trasladado como fabricante, es una cuenta por cobrar. El impuesto que yo a la vez traslade a mis clientes, es una cuenta por pagar al fisco.

Y esa es la diferencia básica para el consumidor final en relación con el nuevo IVA y su $10 \%$, y el antiguo impuesto sobre ingresos mercantiles y su $4 \%$; que el consumidor siempre sabrá que estará pagando el 10 por ciento pero que este 10 es único y no como anteriormente sucedía que se pagaba un $4 \%$ pero era un 4 por ciento acumulado quien sabe cuántas veces (Concamin, 1980, p. 71).

A propósito del efecto cascada del IsIM que hemos señalado, la federación también enfatizó la integración vertical de la actividad económica, que no venía bien con la consolidación del mercado interno. Este inconveniente es claramente planteado por Parás y Jiménez (1972):

Otro defecto de este impuesto, era el de favorecer a la industria integrada en forma vertical, esto es, la que elaborase el producto y lo vendiese directamente al consumidor, ya que en el precio de sus mercancías sólo se incluiría el impuesto causado en la primera y única venta. Por lo contrario, los artículos que hubiesen pasado por varias empresas, antes de convertirse en productos terminados y listos para ser vendidos al consumidor final, incluirían en su precio de venta, el impuesto causado por cada una de las empresas por las que hubiera pasado; y con ello habría operado la imposición acumulativa (Parás y Jiménez, 1972, p. 7).

Este inconveniente del ISIM no sólo representó uno de los principales argumentos federales a favor del IVA, permitió también reconocer a este último como un instrumento fiscal de largo plazo para combatir la inflación.

[...] es necesario reconocer que el Impuesto Sobre Ingresos Mercantiles ha venido perdiendo efectividad, como consecuencia de los cambios registrados en las relaciones comerciales. Sus ventajas iniciales se ven ahora agotadas entre otras razones, porque grava el importe de cada operación de venta, sin deducir el tributo previamente pagado, por lo que su cuantía se incorpora repetidamente en el precio final del consumidor (Ibarra, 1980, p. 157). 
De forma similar a lo ocurrido en 1947 cuando se estableció el ISIm para eliminar los impuestos locales y los renglones del impuesto federal del timbre que recaían sobre la compraventa, la federación, si bien reconocía las ventajas iniciales del impuesto a sustituir, también subrayaba la oportunidad de remplazarlo en virtud de que el desarrollo económico había provocado una mayor complejidad en los procesos de producción y distribución (Gil, 1979, p. 440).

En resumidas cuentas, tal como se lee en la iniciativa de ley del IVA, el gobierno federal justificaba su introducción bajo el argumento de que los efectos acumulativos del IsIM -al provocar distorsiones en los procesos de comercialización- constituían presiones inflacionarias que acentuaban la regresividad del sistema tributario nacional. Además, afirmaban, se perjudicaba a las pequeñas y medianas industrias en relación con las de mayor tamaño que sí estaban integradas verticalmente.

\section{"La decisión mexicana es una decisión política, pero ciega": las críticas en relación con la inflación 10}

La bondadosa valoración que la federación defendió sobre las ventajas del Iva fue, en general, una postura compartida por analistas y políticos de aquellos años. Por su parte, los contribuyentes organizados en las distintas cámaras, salvo ciertas problemáticas administrativas, no mostraron mayor animadversión al respecto. Así, por ejemplo, en el informe de la reunión de análisis de la reforma fiscal de 1979 convocada en febrero de ese año por la Concamin y numerosas personalidades del sector empresarial:

La reunión tuvo por objeto que los [...] funcionarios de la Secretaría de Hacienda, encargados de cumplimentar las citadas reformas, expresaran sus comentarios y contestaran aquellas interrogantes que preocuparan al sector empresarial.

Se habló también sobre la nueva Ley del Impuesto al Valor Agregado, visualizando la diversa temática y problemática que el mismo presenta sobre todo a nivel de administración.

Hubo también un periodo de preguntas y respuestas en el cual los industriales presentes plantearon a dichos funcionarios sus inquietudes llegándose a la conclusión de que cualquier comentario o aclaración que surja en relación con la Ley del Impuesto al Valor Agregado, se haga del conocimiento de las autoridades correspondientes a fin de que, a la fecha de su aplicación, el susodicho impuesto resulte beneficioso y no perjudicial a la economía del país (Confederación de Cámaras Industriales, 1979b, pp. 37-38).

Y al parecer, el gobierno federal cumplió con su cometido. Un mes antes de la entrada en vigor del iva, Alfonso Pandal Graf, vicepresidente de la Concamin, celebraba el establecimiento del iva sin advertir alguna objeción de fondo sobre el mismo y repetía incluso los argumentos federales en pro del conjunto de los cambios fiscales (Confederación de Cámaras Industriales, 1979a).

No obstante, si bien es cierto que el IVA presentaba numerosas ventajas en relación con el IsIM futuras investigaciones deberán estudiarlas con sumo cuidado-, que facilitaron su introducción en 1980, su imposición también suscitó diversas críticas durante el periodo de gracia que la federación definió para su entrada en vigor. La mayoría de las críticas giraron en torno a la oportunidad de

${ }^{10}$ Morales (1979, p. 8). 
establecerlo en el contexto inflacionario de aquellos años. En febrero de 1979, a propósito de una entrevista sobre la introducción del Iva realizada a expertos del Instituto Mexicano de Contadores Públicos, se encuentra un ejemplo de tales críticas:

En realidad, para la mayoría de los analistas la introducción del iva presenta casi solo un inconveniente que con todo no es pequeño ni desdeñable: la inflación. De aquí al final de año, virtualmente, México deberá haber domeñado el espectro inflacionario en un nivel razonable: inferior al $10 \%$. De lo contrario, el IVA llegará a alimentar el fantasma de la inflación y convertirá al país en una verdadera casa de los sustos.

[...] es observación común que en un inicio la aplicación del nuevo impuesto ejercerá una presión alcista en los precios. Parás señala que en términos de la inflación el efecto tiene un doble efecto. Por una parte, presiona sobre los precios en un inicio, dado el inevitable ajuste y descontrol entre los comerciantes y debido a que -si en efecto, como se supone, erradicará gran parte de la evasión- artículos que escapaban parcial o totalmente del Isim elevarán su precio al momento que el iva ejerza su control sobre ellos. Por otra parte, sin embargo, mediante el nuevo gravamen el Estado aumentará su capacidad recaudatoria y sus ingresos, por una vía no inflacionaria directamente, ya que no recurre al camino de aumentar el circulante. Según Daniel de la Garza. Presidente del Instituto Mexicano de Contadores Públicos "es una gran ventaja que el impuesto tenga todo un periodo para sus ajustes e implementación”. Si, en ese lapso -advierte- se dispara excesivamente la inflación, habría que repensar seriamente la aplicación del impuesto, para un tiempo más oportuno (“IVA”, 1979, p. 42).

Si bien se reconocía que el iva no generaría en el largo plazo presiones inflacionarias por ser una figura mejor diseñada que el ISIM, sí se recalcaba que la consecuencia en el corto plazo sería exactamente la contraria debido a los efectos psicológicos que su imposición tendría sobre los consumidores, y a los ajustes contables y administrativos que implicaría para las empresas y la administración pública. Eduardo Turrent (1980) presenta observaciones similares sobre las presiones inflacionarias que inicialmente generaba el IvA aduciendo a las experiencias internacionales. $\mathrm{Al}$ respecto, recordaba, por ejemplo, que en el caso de Holanda y Luxemburgo la introducción del nuevo impuesto estuvo acompañada de un estricto control gubernamental sobre el nivel de precios y el caso de Italia en el que su establecimiento se pospuso por tres años debido al temor de que, tras su entrada en vigor, se reforzaran las presiones inflacionarias en ese país (Turrent, 1980, pp. 23-25).

Otra de las críticas que surgieron fue planteada por un grupo de economistas de la Universidad de Pensilvania agrupados en la Wharton Econometric Forecasting Associates. En una reunión celebrada el 15 y 16 de noviembre en la University City Science de Filadelfia, este centro de investigaciones entonces dedicado a la elaboración de estudios econométricos en países capitalistas y socialistas, entregó un estudio a sus subscritores mexicanos del sector público y privado en el que analizaba las repercusiones de la aplicación del Iva en México ${ }^{11}$ Entre sus observaciones señalaba la inconveniencia de establecerlo en enero debido a la existencia de otras variables que presionaban los precios al alza y que, a diferencia del Iva, no existía alternativa en su implantación. En el reporte se establece:

${ }^{11} \mathrm{Al}$ encuentro asistieron representantes del Banco de México, de Petróleos Mexicanos, de la Comisión Federal de Electricidad, del Instituto Mexicano del Seguro Social, de Grupo Alfa, de Ingenieros Civiles Asociados, de Banco Nacional de México y Multibanca Comermex, véase Morales (1979). 
El mes de enero resulta el más inadecuado para introducir un impuesto que va a afectar los precios y, especialmente, al consumo, ya que enero se caracteriza por ser más inflacionario que otros meses y esta observación histórica de por lo menos los últimos seis años, se verá confirmada por otros hechos sobre los que, a diferencia del IVA, no existe alternativa en cuanto a la fecha de implantación, como son: nuevos precios de productos subsidiados, incrementos de salarios, pago de aguinaldos y el fin del compromiso de precios estables del sector privado (Morales, 1979, p. 7).

La Warthon, además de sugerir que su implantación se postergara para mayo -por ser el periodo que históricamente venía registrando cierta estabilidad en los precios- advirtió que la tasa de $10 \%$, de acuerdo con sus estimaciones, no había sido bien calculada. Según su modelo, con esta tasa se generaría una recaudación de 125000 millones de pesos para 1980 que superarían los 85000 millones que se proyectaban de Isim para el mismo año. Este aumento inicial en la recaudación, recordaban a partir de la experiencia internacional, tampoco era recomendable porque aumentaría la carga fiscal de los impuestos indirectos generando así, un impulso adicional a la inflación que no estaba relacionado con los factores psicológicos y de ajuste administrativo. Afirmaban entonces, que, para evitar este escenario, lo más adecuado era iniciar la aplicación del IVA con una tasa del $8 \%$. Recomendaban al mismo tiempo, establecer subsidios a la carga fiscal en productos básicos y créditos para los inventarios al 31 de diciembre porque ya habían cubierto el pago del ISIM (Morales, 1979, p. 7).

En su conjunto, estos señalamientos cobraban capital importancia si se considera que el control del circulante y los topes cuantitativos al endeudamiento externo neto que habían surgido en el marco del programa de estabilización acordado con el FMI tras la devaluación de 1976, no habían sido del todo satisfactorios para detener el alza de precios (Tello, 2014, pp. 315-316). Si se suma también, que la economía nacional importó inflación a propósito del aumento del precio internacional del petróleo en 1979, se entiende la trascendencia de dichas observaciones. Con todo, y a pesar de que las distintas voces advirtieron que no era el momento adecuado, la federación no postergó su establecimiento argumentando que el periodo que se concedió para su entrada en vigor había servido para impulsar un proceso de divulgación sobre el tránsito ISIM-IVA que permitió reducir los riesgos psicológicos del posible impacto inflacionario y preparar los órganos administrativos que se encargarían del nuevo gravamen. De esta manera, en la iniciativa de la Ley de Ingresos para 1980, respecto a la imposición del IVA, se lee:

El haber programado que la nueva ley iniciara su vigencia doce meses después de haber sido aprobada permitió una comunicación amplia con todos los sectores sociales, a fin de recoger sus observaciones constructivas y revisar a fondo su contenido y concordancia con la realidad económica nacional, así como preparar los órganos administrativos que habrán de manejar el nuevo sistema.

Como resultado de estas labores preparatorias se proponen modificaciones orientadas a esclarecer conceptos y su expresión en la Ley, a facilitar el tránsito de un sistema a otro y a reducir los riesgos psicológicos de un posible impacto inflacionario, principalmente sobre los artículos que determinan los niveles de vida de los grupos mayoritarios de la población. (Ibarra, 1980, p. 292-293) 
Entre las modificaciones que se señalan en la cita, se encuentran las sugerencias de la Wharton: se establecieron exenciones a los bienes que formaban parte de la canasta básica y los créditos a los inventarios. Para David Ibarra, entonces Secretario de Hacienda, estas disposiciones coadyuvarían a que el Iva no fuera inflacionario. Si se diera el caso contrario, afirmaba días antes de que entrara en vigor el IVA, obedecería a que aún predominaban "la mala fe y la especulación” (“IVA”, 1979, p. 21).

Ahora bien, si se considera que el Índice Nacional de Precios durante 1980 experimentó un incremento de 29.8 \% que superó en casi diez puntos porcentuales al registrado en el año anterior (Banco de México, 1981), se evidencia por supuesto, que todas las medidas impulsadas por la federación durante 1979 no fueron suficientes para atenuar los efectos inflacionarios que generó la introducción del IVA. La inflación en constante ascenso a partir de 1981 y el escenario económico que desembocaría en la crisis de 1982, son muestra inequívoca de dos cuestiones. La primera, como todos conocemos, es que el repunte económico de finales de 1978 no fue duradero. La segunda, es que la federación no frenó su intento por establecer el iva a pesar de ello y de las críticas señaladas en ese sentido. En términos de la inflación, en pocas palabras, el escenario no estaba dado para establecerlo ${ }^{12}$ El mismo López Portillo así lo reconoció:

[...] Me lancé a implantar el Iva y honestamente me arrepentí después, fundamentalmente por razones de oportunidad. [...] La inflación no estaba controlada; [...] pero se combatía. El IVA responsabilidad exclusiva del Estado, por las razones que se quiera, rompió el argumento de la disciplina antiinflacionaria y todas las clases y factores, se sintieron con derecho a aspirar sus propias alzas. Y con ello, la inflación adquirió virulencia peligrosa. Reconozco que las condiciones para implantar el IVA no estaban dadas. iClaro! Ahora el iva es un factor de control fiscal que ya pagó su precio y sirve al país. Pero el precio político lo pagué entonces (López, 1988, p. 894).

Entre las preguntas que surgen a propósito de lo que recién se ha planteado es el por qué se estableció a pesar de que el escenario económico ya no era el adecuado. Un elemento que puede ayudar a responder esta cuestión es la delicada relación que existía para entonces, entre el gobierno y los empresarios. Si consideramos los enfrentamientos que este sector tuvo con Echeverría a propósito de la política económica que éste impulsó, e incluso, la conformación del Consejo Coordinador Empresarial (CEE) en mayo de 1975 como muestra de la fuerza política que adquiría la iniciativa privada, se identifica un cerco importante para la libre acción federal en términos tributarios. Esta hipótesis no parece tan desatinada si se tiene en cuenta que, desde mediados de la década de los sesenta, el Impuesto Sobre la Renta no tuvo modificaciones de gran trascendencia ${ }^{13}$ Futuras investigaciones sobre esta problemática arrogaran importantes hallazgos para entender por qué fue así. Pero lo cierto es que, en estos años, como también reconocía la Wharton, se dio prioridad a las modificaciones en la imposición indirecta debido a los problemas que implicaría con la iniciativa privada reformar la imposición directa. (Morales, 1979, p. 8). López Portillo describe el problema en los siguientes términos:

\footnotetext{
${ }^{12}$ Sobre la inflación en México durante la década de 1970, véase Cárdenas (2015).

${ }^{13}$ Sobre las implicaciones político-tributarias de las reformas al ISR de 1961 y 1964, véase Urquidi, Aboites y Unda (2011).
} 
Si me echo de cabeza por una Reforma Fiscal, tendrá que ser no sólo por los efectos recaudatorios, sino por los redistributivos y la única manera de hacerlo es afectando al capital, primero mediante la anulación del anonimato y después subiendo tasas. [...]El cerco de los intereses es tremendo. Sólo un cambio radical de Sistema, me permitiría avanzar hacia donde quisiera; [...]. Estoy, realmente, en el más grande dilema de mi Gobierno. Hago una reforma a fondo, totalizando, globalizando todo ingreso mediante la anulación del anonimato... Hago una reforma a medias, fundamentalmente en el área de impuestos indirectos, el valor agregado, con efectos que golpearían a todos, pero particularmente y otra vez, a los más fregados (López, 1988, p. 643).

Y en efecto, como sabemos, se estableció el IVA. No era lo mismo reformar el isR que ya recaía sobre los ingresos del capital y que reportaba grandes ingresos tributarios para la federación, que establecer un impuesto, el IvA, en el que la iniciativa privada sólo fungiría como intermediario entre el fisco y el consumidor final debido a la traslación del impuesto. José Mauricio Fernández (1979), destacado fiscalista de aquellos años, plantea, en relación con este mecanismo establecido en el artículo $1^{\circ}$ de la ley federal del Iva:

De conformidad a este precepto se autoriza al causante para que traslade el Impuesto al Valor Agregado a las personas que adquieran los bienes, los usen o gocen temporalmente, o reciban los servicios. Llamase traslado al acto por el cual "el contribuyente" cobra o carga el impuesto a dichas personas. De donde resulta que por virtud de este acto se lleva a cabo una remoción en cuanto a calidad de sujeto pasivo. Es decir, económicamente -no jurídicamente-, los sujetos a quienes se atribuye la calidad de causante de acuerdo con este artículo 1o., pueden traspasar la carga del impuesto a un tercero. Consecuentemente, por virtud de la traslación, quien deviene formal y jurídicamente en contribuyente, se convierte simplemente en un recaudador. Económicamente se produce así una remoción, cambio o mudanza en cuanto a quién realmente soporta la carga del impuesto.

[...] Contemplada así la mecánica estructural y operativa del impuesto, tenemos que el llamado "contribuyente", [...], simplemente hace las veces de un [...] encargado de llevar al cabo la colecta de percepciones que a favor de la Hacienda Pública generan los hechos imponibles que al efecto tipifica la Ley en estudio (Fernández, 1979, pp. 69-70).

Quizá esta es la razón principal por la que no se encuentra alguna oposición importante por parte de los empresarios en relación con su establecimiento. Es también esta situación por la que la Wharton Econometric Forescating Associates afirmaba que la imposición del Iva en 1980 fue una decisión política en tanto que también respondió a la importancia de no generar algún conflicto con la iniciativa privada a través de la modificación de la imposición indirecta. Pero ciega, al hacer caso omiso al escenario económico que, en términos inflacionarios, no favorecía su imposición (Morales, 1979, p. 8).

Sin embargo, el contenido político de la decisión mexicana también está relacionado con las implicaciones que el iva tuvo en la relación fiscal entre el gobierno federal y los estados. Si bien esta problemática representa un tema en sí mismo de investigación que futuros estudios deben abordar si se quiere entender el federalismo fiscal mexicano del finales del siglo xx, sí podemos al 
menos resaltar un elemento de importancia: con la estructura del IVA, en la que el contribuyente funge como recaudador del impuesto federal, la entidad federativa donde se lleva a cabo la venta y donde se genera el valor agregado, deja de tener importancia para efectos de la recaudación del impuesto. De aquí, resulta que las participaciones ya no podrían asignarse con base en la recaudación local como sucedía bajo el esquema del Isım 14 Bajo esta dinámica, se creó el Fondo General de Participaciones que sustentó la nueva ley de coordinación fiscal que entró en vigor, al igual que el IVA, el 1 de enero de 1980. A través de la existencia de este, la federación dejaba de participar la recaudación por figura tributaria para comenzar a repartirla en función de un solo conjunto de ingresos constituido por una proporción de sus ingresos totales anuales. Las implicaciones políticas que estas medidas tuvieron en términos de la distribución de las facultades tributarias no fueron de poca importancia. Con el IVA, la federación recargaba la recaudación en un agente económico (el contribuyente) y dejaba de lado en la misma, a una entidad política (los estados). La centralización fiscal estaba, nos parece, consolidada.

\section{Consideraciones finales}

El estudio que hemos presentado sobre el establecimiento del impuesto al valor agregado en México sugiere varias cuestiones. En primer lugar, se ubica la necesidad de repensar la conclusión del proceso de centralización fiscal del comercio y la industria. Las investigaciones que han abordado esta problemática han afirmado que la coordinación política del ramo concluyó en 1971 cuando la federación estableció una participación del $45 \%$ sobre la recaudación de la sobretasa de $10 \%$ sobre la compraventa de artículos de lujo. La idea central de ese planteamiento como señala Aboites (2003) es que la centralización política se alcanzó a través de una mejor distribución del ingreso fiscal a favor de las entidades federativas. Sin embargo, como se ha mostrado, el proceso concluyó hasta 1973 tras la imposición de una tasa única de 4 \% que obligó a los estados aun faltantes a firmar el respectivo convenio de coordinación. Lo que se demostró en este sentido es que los estados se coordinaron por un mecanismo de coerción política -la tasa única de $4 \%$ - y no exclusivamente por el aumento de la participación que les correspondía.

Bajo este nuevo planteamiento, los fracasados esfuerzos federales por establecer el IvA durante la década de 1970 desempeñaron un papel por demás importante en tanto evidenciaron la necesidad de concluir la centralización fiscal del ramo si es que se pretendía avanzar en el establecimiento del impuesto sobre el consumo final. Lo que se puede deducir en este sentido, es que las dificultades de impulsar la coordinación con dos figuras tributarias, -es decir, con el Isim y el iva como se pretendió con el anteproyecto de 1968 y el proyecto de 1969-, en tanto imprimieron un carácter ineludible a la reforma de 1973, facilitaron en términos políticos el posterior establecimiento del IVA en 1978.

Para finales de la década de 1970, cuando la federación retomó los esfuerzos por establecer el IVA tras el repunte que registró la actividad económica en 1978, no hubo mayor obstáculo en relación con las entidades federativas. Las principales críticas fueron de carácter económico y giraron alrededor de la oportunidad de establecerlo en un escenario que ya se caracterizaba de inflacionario. El discurso en torno a los preparativos administrativos y las labores de difusión que

\footnotetext{
${ }^{14}$ Bajo el esquema anterior a 1973 cada entidad federativa cobraba una participación de la recaudación federal del IsIM a través de una sobretasa de 1.2\%. Después, bajo el esquema de tasa única, la federación otorgaba $45 \%$ de la recaudación local.
} 
se emprendieron durante el año que se concedió para su entrada en vigor fueron elementos que permitieron que la federación no postergara su establecimiento. Estas críticas no detuvieron la imposición del IVA en tanto que el arreglo fiscal con los causantes no resultaba conflictivo. Al final de cuentas, estos no eran el objeto directo de la reforma fiscal: no se impulsó una reforma al IsR y con el nuevo impuesto, estos fungían como recaudadores del IVA. Futuras investigaciones tendrán que indagar las respuestas de los consumidores finales sobre los que efectivamente recaía la carga tributaria.

En segundo lugar, se encuentra el conjunto de preguntas que surgen a propósito de estos planteamientos. Algunas de carácter político que pueden matizar el contenido del federalismo fiscal de aquellos años, tienen su origen en el diseño mismo del impuesto. Bajo el esquema del iva, el lugar donde se celebra la venta ya no tiene importancia para efectos de la repartición de las participaciones. De ahí, el surgimiento del Sistema Nacional de Coordinación Fiscal que consagró la centralización fiscal del comercio y la industria al tiempo que redefinió por completo y en su conjunto, las relaciones fiscales entre la federación y los estados. ¿Cómo se definió el ingreso fiscal bajo ese sistema?, ¿qué implicaciones tuvo en la repartición del ingreso fiscal?, ¿̇uáles fueron los espacios, formas o recursos con los que contaban los estados bajo ese sistema para hacerse de más recursos?, ¿cuáles fueron las implicaciones para el resto de los ramos tributarios? Con la misma intención de indagar sobre los arreglos fiscales, se puede analizar la relación entre los esfuerzos federales fracasados por reformar el ISR y las reformas exitosas a la imposición indirecta. La premura del gobierno por establecer el IVA en un escenario que exigía una reforma tributaria a finales de la década de 1960, obedeció en alguna medida al cerco de intereses de los empresarios por modificar el ISR. ¿En qué otros momentos de la historia fiscal mexicana del siglo xx se ubica esta relación? Si fue el caso, ¿qué elementos aporta para caracterizar la relación fisco-causantes? y ¿cómo esta facilitó la centralización fiscal del comercio y la industria?

Surgen también posibilidades analíticas relacionadas con la cuestión administrativa. ¿Cuáles fueron los cambios que se impulsaron en el sector público y las empresas?, ¿̇cómo se redefinió la función pública para dar espacio a la administración de un impuesto nuevo?, ¿qué tipo de dificultades se enfrentaron y cómo se resolvieron? Y de nuevo la cuestión política, ¿cuáles fueron las quejas, pronunciamientos o declaraciones de los consumidores ante el nuevo impuesto?, ¿̇cómo se resolvieron y cómo los cambios del IVA, posteriores a 1980, respondieron a dichos problemas? Un último aspecto que puede ser analizado es de carácter económico. Vale la pena, por ejemplo, hacer una comparación más fina entre el proyecto de 1968 y el anteproyecto de 1969 que permita contar con una noción más clara del Iva que posibilite el planteamiento de hipótesis de trabajo alrededor de su relación con la actividad económica. Esta pregunta cobra importancia si consideramos que, en efecto, el Iva logró consolidarse como uno de los pilares más significativos del sistema tributario mexicano. Así mismo, se puede poner cuidado en su relación con el nuevo modelo de crecimiento económico basado en las exportaciones y el ingreso de la economía mexicana en convenios internacionales como el Acuerdo General sobre Aranceles Aduaneros y Comercio (GATT). En este sentido se puede indagar, por ejemplo, su estudio a partir de la tasa de $6 \%$ que se estableció para las zonas fronterizas. Ojalá se emprendan las investigaciones necesarias para responder estas y demás preguntas que permitan entender la frágil y complicada fiscalidad mexicana. Por lo pronto, la revisión de la sustitución IsIM-IVA permite identificar la coordinación fiscal, al menos del comercio y la industria, como un problema definido también por un conjunto de dificultades políticas y económicas que deben estar consideradas si se pretende una comprensión mínima de la fiscalidad mexicana contemporánea. 


\section{LISTA DE REFERENCIAS}

Aboites, L. (2003). Excepciones y privilegios: modernización tributaria y centralización en México, 19221972. México: El Colegio de México.

Anónimo (2009, noviembre 25). Alan Tait, Economist. The Scotsman. Scotland's National Newespaper. Recuperado de https://www.scotsman.com/

Banco de México. Sexagésima Tercera Asamblea General Ordinaria de Accionistas (1981). Informe anual, 1980. México: Banco de México. Recuperado de http://www.anterior.banxico.org.mx/

Banco Mundial (2018). Rentas del petróleo (Porcentaje del PIB) | Data [Conjunto de datos]. Recuperado de https://datos.bancomundial.org/

Beteta, R. (1951). Tres años de política hacendaria, 1947-1948-1949: perspectiva y acción. México: Secretaría de Hacienda y Crédito Público.

Cabrera, A. A. (2011). Series estadísticas de la economía mexicana en el siglo XX. Economía Informa, 369, 63-85.

Cárdenas, E. (2015). El largo curso de la economía mexicana: de 1780 a nuestros días. México: Fondo de Cultura Económica/El Colegio de México.

Comunidad Económica Europea [CEE] (1967, 14 de abril). Primera Directiva del Consejo de 11 de abril de 1967 en materia de armonización de las legislaciones de Estados miembros relativas a los impuestos sobre el volumen de los negocios. Diario Oficial de las Comunidades Europeas, 1(9), 3-5. Recuperado de https://eur-lex.europa.eu/

Confederación de Cámaras Industriales (1979a). Exposición de motivos de la primera reunión nacional de industrialización. Revista de la Confederación de Cámaras Industriales [Concamin], 711, 9-20.

Confederación de Cámaras Industriales (1979b). Reunión de análisis de la reforma fiscal de 1979. Revista de la Confederación de Cámaras Industriales [Concamin], 703, 37-38.

Confederación de Cámaras Industriales (1980). Algunas consideraciones sobre la reforma fiscal. Revista de la Confederación de Cámaras Industriales [Concamin], 712, 14-15.

Congreso de los Estados Unidos Mexicanos. (1978, diciembre 29). Ley del Impuesto al Valor Agregado. Diario oficial de la Federación, 107.

Egret, G. (1979). El impuesto sobre el valor añadido. Barcelona: Oikos-Tau.

Elizondo, C. (1994). In Search of Revenue: Tax Reform in Mexico under the Administrations of Echeverría and Salinas. Journal of Latin American Studies, 26(1), 159-190. DOI:10.1017/S002 2216X00018885

Escoto, H. (1972). Puntos de vista y observaciones que los técnicos del sector empresarial presentan al señor licenciado Roberto DAddona, administrador general de impuestos al ingreso, respecto del Anteproyecto de "Ley Federal de Impuesto Sobre Egresos". En A. Parás y M. Jiménez, Impuesto al valor agregado. México: Centro de Investigación Tributaria.

Fernández, J. M. (1979). Manual de aplicación del Impuesto al Valor Agregado. México: Jus.

García, P. (1982). La evasión fiscal en México: un estudio comparativo del impuesto sobre ingresos mercantiles con el impuesto al valor agregado. México: Universidad Autónoma Metropolitana.

Gil, G. (1979). Derecho fiscal. Notas sobre la introducción del impuesto al valor agregado. Gaceta Informativa de Legislación y Jurisprudencia, 1(27), 439-448.

Gracida, E. M. (2002). El siglo xx mexicano: un capítulo de su historia, 1940-1982. México: Universidad Nacional Autónoma de México. 
Ibarra, D. (1980). Política financiera y hacendaria. México: Secretaría de Hacienda y Crédito Público.

Instituto Nacional de Estadística Geografía e Informática (1999). Estadísticas históricas de México. México: Autor.

Instituto para el Desarrollo Técnico, Hacienda Pública de Estados y Municipios (1975). Documentos. INDETEC, 10, 30-35.

IVA: El valor de un impuesto agregado (1979). Expansión, 11(258), 41-42.

Lieberman, E. S. (2002). Taxation data as indicators of state-society relations: Possibilities and pitfalls in cross-national research. Studies in Comparative International Development, 36(4), 89115. DOI: $10.1007 / \mathrm{BF} 02686334$

López, J. (1980). Exposición de motivos ante la Cámara de Diputados de la Iniciativa de Ley de Ingresos de la Federación para 1978. En D. Ibarra, Política financiera y hacendaria. México: Secretaría de Hacienda y Crédito Público.

López, J. (1988). Mis tiempos: biografía y testimonio político. México: Fernández Editores.

Márquez, G. (2012). Avances y retos de la Hacienda Pública en México. En Secretaría de Hacienda y Crédito Público (ed.), 200 años de la Hacienda Pública en México. México: Secretaría de Hacienda y Crédito Público.

Memorial de 04 de febrero de 1948 (1984). (No. exp. 564.1/376). Archivo General de la Nación, Fondo Miguel Alemán, México.

México. Subsecretaría de Ingresos (1973). Bases para la regionalización de la administración fiscal federal. México: Secretaría de Hacienda y Crédito Público.

México. Subsecretaría de Ingresos (1976). Ley federal del impuesto sobre ingresos mercantiles: evolución histórica. México: Secretaría de Hacienda y Crédito Público.

Molina, M. A. (2016). La coordinación del sistema tributario del comercio y la industria en México: el Impuesto Sobre Ingresos Mercantiles (ISIM), 1947-1980 (Tesis de doctorado). Instituto de Investigaciones Dr. José María Luis Mora, México.

Morales, I. (1979). El IVA, más inflacionario de lo previsto. Alza de precios del $21 \%$, irreversible, en 1980: Wharton Econometric. Proceso, 2208, 6-9.

Moreno-Brid, J. C. y Ros, J. (2010). Desarrollo y crecimiento en la economía mexicana: una perspectiva histórica. México: Fondo de Cultura Económica.

Navarro, J. (1973). Participación en el rendimiento del Impuesto Federal Sobre Ingresos Mercantiles, en función del domicilio del causante o de la fuente de riqueza. En Subsecretaría de Ingresos, Primer informe sobre las relaciones fiscales entre la federación y los estados. México: Secretaría de Hacienda y Crédito Público.

Parás, A. y Jiménez, M. (1972). Impuesto al valor agregado. México: Centro de Investigación Tributaria.

Presidentes de América (1967). Declaración de los presidentes de América. El Trimestre Económico, 34(3), 535-550.

Secretaria de Hacienda y Crédito Público (1973). Coordinación total de federación y estados para el cobro de impuestos mercantiles. Financiera y Hacienda, 2, 19-31.

Secretaría de Hacienda y Crédito Público y Gobierno del Estado de Morelos (1950). Convenio celebrado entre la Secretaría de Hacienda y Crédito Público y el Gobierno del Estado de Morelos para la coordinación en el cobro del Impuesto Sobre Ingresos Mercantiles. Diario Oficial de la Federación. Recuperado de http://www.dof.gob.mx 
Tello, C. (2014). La economía política de las finanzas públicas: México, 1917-2014. México: Universidad Nacional Autónoma de México.

Turrent, E. (1980). El Impuesto al valor agregado. El caso de México. México: Universidad Autónoma Metropolitana.

Unda, M. (2017). A tale of two taxes: The diverging fates of the federal property and income tax decrees in post-revolutionary Mexico. Investigaciones de Historia Económica - Economic History Research, 13(2), 107-116. DOI: 10.1016/j.ihe.2016.02.002

Urquidi, V. L., Aboites, L. y Unda Gutiérrez, M. (2011). El fracaso de la reforma fiscal de 1961: artículos publicados y documentos del archivo de Victor L. Urquidi en torno a la cuestión tributaria en México. México: Colegio de México.

Yáñez, M. (1958). El problema fiscal en las distintas etapas de nuestra organización política (vol. 6). México: Secretaría de Hacienda y Crédito Público. 